\title{
A Review on Translation Studies from the Perspective of Post-modernism Philosophy
}

\author{
Rongliang Niu \\ School of Foreign Languages \\ Changchun University of Technology \\ Changchun, China
}

\begin{abstract}
Post-modernism is a universal cultural trend in western developed countries in the $1960 \mathrm{~s}$, and post-modernism philosophy is the fundamental and important component of post-modernism. In essence, post-modernism philosophy is a different way of thinking from modern philosophy, and it is characterized by the emphasis on the negative, non-central, anti-orthodox, uncertain, and diversified concepts. In the aspect of methodology, post-modern philosophy is characterized by Derrida's deconstructionism; in the aspect of epistemology, it is the rejection of meaning's simplicity fixity of essential-ism philosophy concepts. Post-modernism philosophy is the deconstruction of modern philosophy, which has profound and great significance on contemporary translation studies. In the academic expressions of contemporary translation studies, there are many different viewpoints, for example, negation of the meaning's fixity of the source language text, challenging fidelity as the translation standard, putting foreignization strategy on an important position, and emphasis on translators' subjectivity, etc. Under the influence of post-modernism philosophy, deconstructionism was introduced into translation studies, which challenged the traditional translation logo-centrism; post-colonialism was also introduced into translation studies, which aimed to improve the conditions of translators to resist the hegemony of the developed countries' cultures; and feminism translation theory treated gender as a point-cut, which challenged and rebelled the traditional translation theories.
\end{abstract}

Keywords-translation studies; post-modernism; postmodernism philosophy

\section{INTRODUCTION}

Postmodernism was a cultural movement that arose on the both sides of the Atlantic Ocean in the 1960s. In essence, it is a cultural and social movement characterized by deconstruction and criticism. [1] In the aspect of methodology, post-modern philosophy is characterized by Derrida's deconstructionism; in the aspect of epistemology, it is the rejection of meaning's simplicity fixity of essential-ism philosophy concepts. Because of the introduction of Foucault's theory of power discourse into translation studies, postmodernism exerted an important influence on translation studies. Since the 1970s, postmodernism had had great and profound significance on the construction of these translation theories of deconstructionism, post-colonialism and feminism. In 1976, the International Federation of translators was held in Belgium, which made direct contributions to the birth of the cultural turn in translation studies. [2] Then, Zohar's poly-system theory, Toury's descriptive translation studies, Lefevere's manipulation and rewriting theory, Bassnett's cultural translation concepts sprang out like mashroom. At the end of the 1980s, post-colonialism had become a newly-flourished trend in western literary circles. In the post-colonialism translation theory, translation strategy is not only regarded as the problem of language and translation, but also treated as the subversive, political and cultural strategy. And the post-colonialism translation theory aims to improve the conditions of translators to resist the hegemony of the western developed countries' cultures. Under the influence of deconstructionism, feminism movement surged forward in the 1960s in the Western countries. The birth of postmodernism translation studies has got rid of the fetters of the philology translation theories and the linguistic translation theories. It reveals the different influences of politics, power, ideology and other social factors on the construction of translation theories, cultural systems, national literature, and the identification of national culture. [3]

\section{PhILOSOPHICAL Motivation OF POST-MODERNISM TRANSLATION THEORIES}

Post-modernism translation theories are the great innovations in the history of translation studies. As the open system, translation theories inevitably receive the influences of deconstructionism, post-colonialism and feminism. With the advent of post-modernism translation theories, powerdiscourse theory was introduced into translation studies, which changed the paradigm of translation studies, improved the status of translators, and expanded the scope of translation studies. Specifically speaking, post-modernism translation theories include deconstructionism translation theories, post-colonialism translation theory and feminism translation theory, etc. [4]

Benjamin has always been recognized as the founder of deconstructionism translation theories. Benjamin made a brilliant exposition from the perspective of ontology, and his thoughts on translation studies had provoked re-thinking in western translation studies circles since the 1960s, broadened the scope of translation studies, and put the studies of translation practice on the higher position of language and philosophy. In Benjamin's viewpoint, translation is a way of pursuing "pure language", and his thought about translation is closely related to his language religious beliefs. In the 
process of re-creating the source language text, the goal of translation is to rescue the "pure language" from the source language text. Therefore, the paradox of Untranslatability in linguistic philosophy does not exist. In Benjamin's opinion, the translatability of the source language text depends on the qualified translator, the necessity of translation. As the result, the status of translator and translation text will be raised to the same height with the author and the source language text, which theoretically improves the subjectivity of translators.

The philosophical thoughts of deconstructionism was introduced into translation studies by Derrida, which tried to break the pattern of the traditional metaphysical translation studies. He believed that There's no fixed meaning in Translation, deconstructionism was closely related with translation, the concept of "differance" indicated that there were some subtle phenomena in the process of translating, which broadened the scope of translation studies, and provided new ways to analyze the differences in translation. In his viewpoint, all texts have the characteristics of intertextuality. In the process of translating, the culture and context lived by the source language text can be reconstructed because of the conversion of language.

Hermeneutics is a new western philosophy which emerged in the 1960s, and the representatives of this philosophy are Heidegger and Gadamer. This philosophy objects the traditional translation theories, and no longer merely pursues the objective meaning. In Gadamer's opinion, understanding is creative and generative. Because of different historical backgrounds and values, it is inevitable to witness the different translation strategies and different translation versions. Gadamer and Heidegger's new concept "pre-understanding" was introduced to his other important concept "Horizon", and they believed there were two different horizons in the process of translating, i.e. Reader's horizon and text's horizon. In essence, translation is the meeting of the two horizons, and is the dialogue between these two horizons' differences. Hermeneutics reaffirms the importance of translators' roles in the process of translating. Therefore, translators will inevitably have the unique cultural and historical characteristics in the process of interpreting and translating a certain work. [5]

Traditionally speaking, translation is based on the concept of reality, representation and knowledge in Western philosophy. Under the influence of deconstructionism, postcolonialism emerged in the1970s in the west countries, and it was an academic thought with the characteristics of strong political ideologies and cultural criticism, which mainly focused on the discourse between the suzerain states and former colonies. The three representatives of postcolonialism translation theories are Saeed, Spivak and Bhabha. At the same time, Niranjana, Venuti, Robinson, Simon, Tymoczko are also the famous post-colonialism translation theorists. They focused on the core issues of power relations, politics in translation, and domestication and foreignization, and analyzed the issues of culture and politics in the different historical contexts and from the different perspectives.
Feminism and postmodernism are both similar and different. In the context of post-modernism, She wants to keep her independence and borrow other post-modernism theories as a weapon to deconstruct patriarchy. Under the influence of deconstructionism, feminism movement surged forward in the 1960s in the Western countries. The ideological war initiated by the intellectual women has spread to all aspects of our society, such as politics, culture, literature and so on. For more than two thousand years, the circles of translation studies have filled with a wide variety of gender metaphors, for example, comparing translation to "unfaithful beauty", i.e. translation in the same position of women. The hierarchy relationship between the source language text and target language text is closely linked with the images between male and female. As the result, the source language texts are regarded as the strong and productive men, and the target language texts are treated as the faint women in the low status. In the viewpoint of the western feminism translation theorists, translation is in such a weak position that is the result of long suppression from patriarchy. From the perspective of the similarities between feminism and translation, the feminism translation theorists hold that there is a serious problem of sexism in translation, and they begin to suspect the translation theories which contain male centrism. [6]

\section{COMPREHENSIVE ANALYSIS OF TRANSLATION STUDIES SCHOOLS FROM THE PERSPECTIVE OF POST- MODERNISM PHILOSOPHY}

\section{A. The Cultural Schools' Theories of Translation Studies}

Since the 1970s, translation studies have begun to break through the perspective of linguistics and turned to pay attentions to these factors of society, history and culture, etc. Therefore, the academic circles call it the cultural turn of translation studies. The cultural schools' theories of translation studies mainly include poly-system studies, translation norms theory, and rewriting and manipulation theory, etc. [7]

1) Poly-system Theory: Through the research of different forms of literature, the Israeli scholar Even Zohar pointed out that translation literature was also a form of literature, as the same as other literature forms, such as poetry, children's books, popular books, and these all different forms literature constituted the literary system of a country or a nation; at the same time, the literary system itself was also a subsystem that was closely connected with language, politics, economy, ideology and other symbols governed by human's communication, and they formed a whole system: a much larger poly-system. [7] Even Zohar took translation literature into the contexts of literature, society, and culture, and he pointed out that these works would be survived and turned into classics, which were recognized by the ruling class; and other works would be gradually forgotten, which were not classics. The innovation of Even Zohar's transation studies lie in which he put translation activities with the strong position and weak position of cultures together. 
2) Translation Norms Theory:Toury is the Israeli translation theorist, and he holds that translation studies should be based on the target language, and translation is a cultural fact existing in the target culture system. [8] He believes that the social and cultural norms in the reception culture or target language system dominate the translators' aesthetic expectations and thus influence the translators' translation activities. In the process of translation studies, the researchers need to put these related parameters in translation text into the categories of translation studies, and these factors are as follows: politics, language, culture, history, and etc. In Toury's viewpoint, translators are subjected to three norms in the process of translating. Preliminary norms determine the selection of source language text, i.e. translation policies. Initial norms determine the general tendency of translator's translating, i.e. tending to the source language or translation texts' cultures and readers' habits. Operational norms can be divided into matricial norms (these norms that restrict translation principles to the macro structure extent) and textual linguistic norms (these norms that influence translation principles to the micro structure extent). [9]

On the basis of Toury's studies, Hermans further broadened the fields of translation norms, and these factors in the post-translating stage are taken into his studies. In Hermans's viewpoint, translation system is an independent existing social system from the perspective of linguistics, and it has unique functions and structures of itself, so it is self-disciplined. However, translation system must cater to and interact with other systems, and submit itself to the mainstream discourse of the client system from the perspective of culture, so it is heteronomy. The most important thing in norms studies should be based on the translation texts, and followed by the related para-texts and meta-texts. The study of translation texts is mainly from the perspective of self-discipline to find out the principles in languages' transformation that must be followed. However, the study of para-texts and meta-texts is mainly from the perspective of heteronomy to reveal these factors which are closely linked with translation system. [10]

3) Rewriting and the Manipulation Theory: In Lefevere's book, Rewriting and the Manipulation of Literary Fame, he gave a detailed description of rewriting and the manipulation theory. [11] Lefevere believed that non-professional readers became increasingly dominant in the global mainstream of nowadays cultural markets, it was the re-writer, not the writer that decided the fate of literature. There are two factors that constrain the movement of the literature system and keep it in synchronous interaction with other sub-systems; one factor comes from the internal system, and the other beyond the system. Thus, translation regarded as rewriting is mainly limited by three aspects: ideology, poetics and patronage. Ideology is not only confined to the political category, but also refers to the framework for regulating public behaviors, customs and beliefs, and ideology may be which the translators believe in, or it may be that sponsors impose it on the translators in the form of sponsorship. There are two aspects in poetics : on the one hand, literary skills, genres, themes, characters, archetypes, scenes and features; on the other hand, the role of literature as a whole in the social system. Patronage specifically refers to the forces that can promote or hinder the reading, writing, or rewriting of literature. The three elements of rewriting and the manipulation theory are to clarify that the translation and dissemination of literature are subject to the ideology, poetics and patronage of the target cultural markets. As the result, translation text is the specific production of specific era's comprehensive factors.

\section{B. Post-colonial Translation Theory}

Throughout the 20th Century, translation studies headed by the western translation theories previewed throughout the world, and the first world countries represented by the United States and Britain had always held the hegemony of the discourse of translation theories. A series of translation theories discourses created by the western translation theorists not only guide the western translation practices, but also directly influence the construction of translation theories and practices of the non-western disadvantageous cultures. On the contrary, the translation theories of the non-western disadvantageous cultures have little influence on the western translation circles, and even sometimes they are in the state of aphasia in cultural expression, communication and interpretation. In Douglas Robinson's book, Translation and Empire: Post-colonial Translation Explained, it is pointed out that the post-colonial translation theory is put forward by the first countries' scholars. Therefore, the subalterns' voices should be listened after the disintegration of colonialism.

Post-colonialism was one of the latest theoretical trends in the western literary theories circle in the late 1980s. As a kind of radical theory criticism discourse, post-colonial theory classify the facts of cultural colonization in the colony into their own research fields, and put the research center from the text form to culture and politics. The post-colonial theory focuses on the analysis of imperialist cultural aggression and the relationship between the suzerains and the colonies, and examines the interplay between colonialism and the western cultures. Post-colonial translation studies focus on the translation practice process from the perspective of post-colonialism and under the different historical conditions. There are many differences of rights among different cultures, and the power struggle and power operation between the two cultures hidden behind the translation process should be concerned. In this way, it aims to deepen the understanding of translation practice by describing inequalities and asymmetries existing in different ethnic groups, cultures, races and languages.

\section{Feminism Translation Theory}

Feminism translation theory is one of the achievements of cultural turn of translation studies and feminism movement in 1970s, and it is the combination of feminism and translation. Before the advent of feminism and feminism translation theory, translation had been regarded as nogender difference, and it was an activity through mechanical 
transformation from one language to another language. Feminism translation theory challenges the traditional translation theories and brings new concepts to translation studies. At the same time, its characteristic of creative treason has also aroused a wide range of criticism. Feminists believe that women's liberation is firstly based on the emancipation of language. The representatives of feminism translation theory are Simon and Flotow. The concepts of feminism translation theory are as follows: eliminating the discrimination against women in translation studies and translation practice, re-defining the relationship between translation text and source language text, and translation not only about the specific language skills, but also including the cultural, ideological factors.

The Western feminism translation theory introduces "female role" into translation, and puts forward his own viewpoints on translation, and it has a tremendous impact on the traditional translation theories. Firstly, feminist translation theory holds that women's translation activities are purposeful and the thoughts of female are brought into translation practice. The feminism translation theorists hold that translation is not a mechanical activity of repetition, but a process of re-creation by female translators. Secondly, in the viewpoints of feminism translation theorists, the translation text is equal to the source language text, and they are complementary. For the readers, hey can not experience the language beauty and the intricate plots of ups and downs from of the source language text without the translation text. Thirdly, the translators' subjectivity is highlighted in the feminism translation theories. In the traditional translation theories, translators should be invisible in the translation activities, the traces of translators should not be seen in the perfect translation texts, and translation is regarded as the mechanical transformation from the source language text to the target language text. In the opinions of the feminism translation theorists, the female translators should be highlighted, they are should not any longer be invisible, and they should speak loudly to express their ideas and experience from the perspective of women's subjectivity.

\section{THE INFLUENCES OF POSTMODERNISM TRANSLATION THEORIES}

Compared with the traditional translation theories, the most obvious characteristic of postmodernism translation theories is to make the focus of translation studies transform from the linguistic level to the cultural level. They reveal the complicated relationships between translation and politics, ideology and other social discourse power factors, and highlight the social factors in translation studies. When Foucault's discourse power theory was introduced into translation studies, dramatic changes emerged in translation studies, the paradigm of translation studies was transformed from structuralism linguistic paradigm to deconstructionism paradigm, the field of translation studies was broadened, and the translators' subjectivity was highlighted.

\section{A. The Paradigm of Translation Studies Is Transformed from Structuralism Linguistic Paradigm to Deconstructionism Paradigm in Postmodernism Translation Theories.}

Before the advent of the postmodern translation theories, philology translation theories and linguistic translation theories are in the dominated position of translation studies. In the viewpoint of philology translation studies school, translation is a form of literary creative writings, which belongs to the category of aesthetics. The paradigm of philology translation studies is a unique paradigm with the characteristics of attaching more importance to experience, which pursues the relevance of aesthetics rather than linguistic equivalence. In the opinion of linguistic translation studies school, translation is an activity of bilingual transformation, its uppermost task is to seek linguistic equivalence, and the purpose of translation is to reproduce the language functions of the source language text as a whole. With the combination of postmodernism and translation studies, culture, politics, power, ideology and other social factors about translation are introduced into the field of translation studies, and translation studies are gradually transformed from prescription to description. The postmodern translation theories are freed from the fetters of the the traditional paradigms of translation studies, and the paradigm deconstructionism translation studies has been deeply rooted in people's hearts .

\section{B. The Field of Translation Studies Is Broadened in Postmodernism Translation Theories}

The postmodernism translation theories are freed from the fetters of traditional paradigms of translation studies, and not only they pay attentions to the linguistic equivalence, but also their research perspectives are extended to culture, politics, philosophy, ideology, power and other social factors. In this way, the field of translation studies is broadened in postmodernism translation theories, and the interdisciplinary characteristics of translation studies are more obvious. Any other discipline can be combined with translation studies, which can open up a new window for people's understanding and translation studies, increase new development space for translation studies, and inject new life into translation studies. After the cultural turn of translation studies, and under the impetus of these different schools of post-modernism translation studies, translation studies gradually get rid of the subordinate position and have become an independent discipline.

\section{The Translators' Subjectivity Is Highlighted in the Postmodernism Translation Theories}

In traditional translation theories, faithfulness is the most important criterion, the invisibility of the translators is emphasized, and different kinds of equivalence are always pursued. With the advent of postmodernism translation theories, the translators' subjectivity is highlighted. Because of postmodernism's no-center consciousness and pluralistic values, the standard of value evaluation is not clear, even completely ambiguous. In this way, people's thoughts are no longer restricted to social ideals, the meanings of life and traditional morality. As a result, people's thoughts are 
completely liberated, which makes people make profound rethinking. In the postmodernism translation theories, the translators' subjectivity is unprecedentedly highlighted.

\section{CONCLUSION}

Under the influence of postmodernism philosophy, the paradigm of translation studies was transformed from structuralism linguistics paradigm to deconstructionism paradigm, and postmodernism translation theories were innovations in the history of translation studies. With the advent of postmodernism translation theories, Foucault's power discourse theory was introduced into translation studies. Under this circumstance, the paradigm of translation studies was changed, the field of translation studies was expanded, and the translator's subjectivity was highlighted. Although there are different schools of translation studies in postmodernism translation theories, these schools are all influenced by Derrida's concept of deconstructionism and Foucault's power discourse theory in epistemology and methodologies. Deconstructionism translation theories, postcolonialism translation theory and feminism translation theory are blended with and infiltrated with each other, in this way, they jointly promote the continuous development of translation studies.

\section{REFERENCES}

[1] Fang Can. Review of Western Post-Modernist Translation Theories[J]. Foreign Theoretical Trends, 2007(11): 82-86.

[2] Song Yi-feng, Liu Chao-xian. Reflections on the post-modernist Translation Theories.[J]. Foreign Language Education , 2006(3): 7680.

[3] Song Yi-feng. Significance of Post-Modernism Translation Studies[J]. Journal of Foreign Languages, 2008(3): 92-96.

[4] Xiang Peng. On Characteristics, Significance and Drawbacks of Postmodernist Translation Theories[J]. Journal of Chongqing Jiaotong University (Social Science Edition), 2012(6): 122-125.

[5] Zhang Yan-feng. From Dichotomy to Pluralism--Translator's Subjectivity Viewed in the Light of Post-Modernism [J]. Journal of Shanxi University (Philosophy \& Social Science), 2008(3): 108-111.

[6] Nirajana. Sitting Translation: History, Post-Structuralism, and the Colonial Context $[\mathrm{M}]$. Berkeley \& Los Angeles: University of California Press, 1992.

[7] Itamar Even-Zohar. Poly-system studies in Poetics today[J]. International Journal for Theory and Analysis of Literature and Communication, 1990.

[8] Gideon Toury. Descriptive Translation Studies and Beyond[M]. Shanghai: Shanghai Foreign Language Education Press, 2004.

[9] Li Tao. Postmodernism:The journey in modern American of Chinese Lyric Literature :from the Perspective of Sinologists[M]. Shanghai: Fudan University Press, 2015.

[10] Theo Hermans. Translation in System: Descriptive and Systemoriented Approach Explained $[\mathrm{M}]$. Shanghai: Shanghai Foreign Language Education Press , 2004.

[11] Andre Lefevere. Translation, Rewriting and the Manipulation of Literary Fame $[\mathrm{M}]$. Shanghai: Shanghai Foreign Language Education Press, 2004. 